\title{
TREATMENT STRATEGY OF PATENT DUCTUS ARTERIOSUS IN PRETERM INFANTS
}

\author{
Edmond PISTULI ${ }^{1}$, Alketa HOXHA (QOSJA) ${ }^{2}$, Ilirjana BAKALLI ${ }^{3}$, Sokol BUBA ${ }^{3}$
}

${ }^{1}$ Pediartics Department, UHC "Nene Tereza", Tirana University, Albania ${ }^{2}$ Neonatology Department, University Hospital for Obstetrics and Gynecology Tirana, Albania, ${ }^{3}$ University Hospital Center "Nene Tereza", Tirana, Albania
Received: April 13, 2013

Accepted: September 20, 2013
Copyright (C) 2013 by University Clinical Center Tuzla. E-mail for permission to publish: paediatricstoday@ukctuzla.ba

\begin{abstract}
Objective - This study was to assess the efficacy and safety of oral ibuprofen and intravenous ibuprofen for the early pharmacological treatment of patent ductus arteriosus (PDA) in preterm infants. Methods - A randomized, single-blinded, controlled study was performed on premature neonates at the neonatal unit tertiary care hospital, from January 2010 to December 2012. The study enrolled 80 preterm infants with gestational age between 28-32 weeks, birth weight $\leq 2000$ g, postnatal age 48-96 h, and with echocardiographically confirmed significant PDA (a duct size $>1.5 \mathrm{~mm}$ ). The preterm infants received either intravenous or oral ibuprofen randomly as an initial dose of 10 $\mathrm{mg} / \mathrm{kg}$, followed by $5 \mathrm{mg} / \mathrm{kg}$ at 24 and $48 \mathrm{~h}$ after the first dose (the first treatment course). Serum creatinine $(\mathrm{sCr})$, blood urea nitrogen (BUN) and urine output (UO) were recorded prior to treatment, before each dose and after the first treatment course. Results - Forty patients were treated with oral ibuprofen and 40 with intravenous ibuprofen in this period. There was no difference between treatment groups in demographics or baseline renal function. After the first course of the treatment, the PDA closed in $28(70 \%)$ of the patients assigned to the oral ibuprofen group, versus 23 (57.5\%) of those enrolled in the intravenous ibuprofen group $(\mathrm{p}=0.35)$. In the evaluation of renal tolerance, none of the patients had oliguria. Moreover, in patients who underwent a second course of intravenous therapy, the urinary output significantly decreased, but the $\mathrm{sCr}$ levels after the first and after the second treatment course did not differ significantly from the baseline for each group. $7.5 \%$ of the intravenous group underwent surgery, versus $0 \%$ of the oral group. $(\mathrm{p}=0.23)$ Conclusions - Successful pharmacological closure of PDA can be achieved by the use of ibuprofen orally or intravenously, without statistically significant difference in efficacy and safety between the two treatments. Patients treated with ibuprofen intravenously probably have a much higher risk of undergoing surgery.
\end{abstract}

Key words: Patent ductus arteriosus - Ibuprofen, Renal function Serum creatinine level • Oliguria.

\section{Introduction}

Patent ductus arteriosus (PDA) is common in very low birth weight (VLBW $\leq 1500 \mathrm{~g}$ ) infants, and is associated with significant mor- bidities and mortality. Left-to-right shunting through the ductus may increase the risk of intraventricular hemorrhage (IVH) $(1,2)$, necrotizing enterocolitis (NEC) (3), bronchopulmonary dysplasia, and death $(4,5)$. 
Pharmacological closure of PDA with indomethacin, a prostaglandin inhibitor, has remained the mainstay of treatment in premature infants over the last three decades. Successful pharmacological closure of PDA with indomethacin was first reported in 1976, with subsequent reports that indomethacin reduced neonatal morbidity $(6,7)$.

However, indomethacin may lead to complications, such as transient or permanent renal dysfunction $(8,9)$, NEC, and reduced cerebral oxygenation (10). These indomethacin-related complications have prompted researchers to seek safer pharmacological treatment for closure of PDA. In recent years another cyclooxygenase inhibitor, ibuprofen, has been proposed for the treatment of PDA, and several randomized controlled trials have shown it to be as efficacious as indomethacin, with possibly fewer adverse effects (11). Recently, ibuprofen lysine was approved by the US Food and Drug Administration (FDA) for use in treatment of PDA for premature infants. However, since renal perfusion, glomerular filtration rate (GFR) and diuresis in early neonatal life strongly depend on the vasodilator effects of prostaglandins (PGs) on the afferent glomerular arterioles $(6,12$, 13), ibuprofen, as is the case with other COX inhibitors, may not be exempt from causing some renal undesirable effects (14).

Moreover, respiratory distress syndrome (RDS) that needs mechanical ventilation, with a high mean airway pressure and/or continuous positive airway pressure, may exert a deleterious effect on renal hemodynamics (15). In fact, any other pathological increases in vasoconstriction during the neonatal period, such as metabolic acidosis, asphyxia and thermic dysregulation also reduce renal perfusion (16). Thus, the neonatal period is characterized by physiological processes with rapid changes, which may profoundly affect the efficacy and safety of any drug therapy, especially because most of the drugs studied are eliminated through the kidney. The intravenous preparations of indomethacin and ibuprofen are available at exorbitant prices, compared with oral ibuprofen, which is less expensive.

\section{Methods}

The study was designed as a prospective, randomized, one blind, study. The adaptive biased-coin randomization method was used to generate the allocation sequence (Urn Randomization Program). The study was conducted in the neonatal intensive care unit (NICU) of the University Hospital for Obstetrics and Gynecology, Tirana, Albania, between January 2010 and December 2012, and was approved by the local ethics committee and by the scientist council of the University. The study enrolled preterm infants with a gestational age (GA) of 28-32 weeks, birth weight $\leq 2000 \mathrm{~g}$, postnatal age 48-96 hours and RDS with significant PDA (30). Color Doppler echocardiography (Aloka, sonde 7.5 Mhz) was performed on all infants, who were clinically suspected of having PDA. This was conducted by a technician under the supervision of a cardiologist, who was blind to the child's name and the treatment being given. PDA was considered echocardiographically significant when we found a duct size $>1.5$ $\mathrm{mm}$. GA was assessed by obstetrical dating criteria, or, when obstetrical data was inadequate, by Ballard examination (September 1991).

Exclusion criteria were major congenital abnormalities, right-to-left ductal shunting, life-threatening infection, grade 3 or 4 $\mathrm{IVH}$, oliguria of less than $1 \mathrm{ml} / \mathrm{kg} / \mathrm{h}$ during the preceding eight hours, serum creatinine concentration $(\mathrm{sCr})$ in excess of $1.6 \mathrm{mg} / \mathrm{dl}$, blood urea nitrogen (BUN) in excess of 60 $\mathrm{mg} / \mathrm{dl}$, thrombocyte count of less than 60 $000 / \mathrm{mm} 3$, clinical bleeding tendency as revealed by haematuria, blood in the gastric aspirate or in the stools, blood in the endo- 
tracheal tube aspirate, oozing from venous or capillary puncture sites, hyperbilirubinemia for which exchange transfusion was required and pulmonary hypertension.

All infants who met the entry criteria first underwent echocardiography and cranial ultrasonography, after which they were treated with either oral ibuprofen (Brufen, Abbot S.r.l, Italy Algofren), where $10 \mathrm{mg} / \mathrm{kg}$ was given via an orogastric tube, which was flushed with $1 \mathrm{ml}$ of sterile water to ensure delivery of the drug, or intravenous ibuprofen (Pedea, Orphan Europe; a vial of $2 \mathrm{ml}$ containing $10 \mathrm{mg}$ of ibuprofen), that was infused over a 15-minute period with a syringe pump. The line was subsequently flushed with saline.

The 2 imaging procedures were again performed 24 hours after each ibuprofen dose. When the PDA was still hemodynamically significant, as demonstrated by echocardiography, and there was no evidence of deterioration in brain ultrasonography, a second dose of ibuprofen $5 \mathrm{mg} / \mathrm{kg}$ was administered. A third equivalent dose was given after another 24 hours if deemed necessary. Before and 24 hours after treatment, all patients were evaluated with a complete blood count, renal function tests: $s \mathrm{Cr}$, BUN and urine output (UO), cranial ultrasonography, and echocardiography. Cranial ultrasound was repeated 1 week after the last ibuprofen dose and again before discharge from the ward. Hematochemical analyses were performed daily in the unit during the first days of life.

RDS was treated with respiratory support (CPAP, intermittent mechanical ventilation or high-frequency ventilation), oxygen supplements, and surfactant (Curosurf, Chiesi, Italy; a vial of $1.5 \mathrm{ml}$ containing $120 \mathrm{mg}$ ) was administered intratracheally at the dosage of 100 to $200 \mathrm{mg} / \mathrm{kg}$. Prophylactic antibiotics were started on admission and stopped after 5 days if blood cultures were negative.

The major outcome of the analysis was success rate closure of the PDA.
Secondary outcomes were: Renal side effects, assessed with measurement of sCr levels, BUN serum levels and UO and Mortality.

\section{Statistical analysis}

For sample size calculation, the power was set at $80 \%$, a commonplace procedure in similar studies. The difference of $25 \%$ was anticipated in the degree of closure in the oral ibuprofen group of $95 \%$. This assumption was based on similar reports from the international literature. The calculation revealed the sample size of 40 subjects in each arm. Paired-samples T-test was used for comparison of mean values between two related (dependent) groups. Chi-square test was used to compare independent proportions between categorical variables. A $p$ value of $<0.05$ was considered significant. Random allocation sequence was generated using the Urn Randomization Program.

\section{Results}

A total of 168 premature infants with GA 28-32 weeks, birth weight $<2000 \mathrm{~g}$ and RDS were admitted to our NICU, from January 2010 to December 2012 and underwent echocardiographic evaluation at the age of 48-96 hours. Ninety-four of them showed significant PDA. Fourteen infants were excluded for several reasons (see Fig. 1), and 80 infants were randomized to have oral ibuprofen or intravenous ibuprofen.

Baseline characteristics were similar between the two groups in the first 96 hours (Table 1).

After the first course of the treatment, the PDA closed in $28(70 \%)$ of the patients assigned to the oral ibuprofen group, versus $23(57.5 \%)$ of those enrolled in the intravenous ibuprofen group $(\mathrm{p}=0.35)$. Six patients $(15 \%)$ in the oral ibuprofen group required a second course of drug therapy, compared 


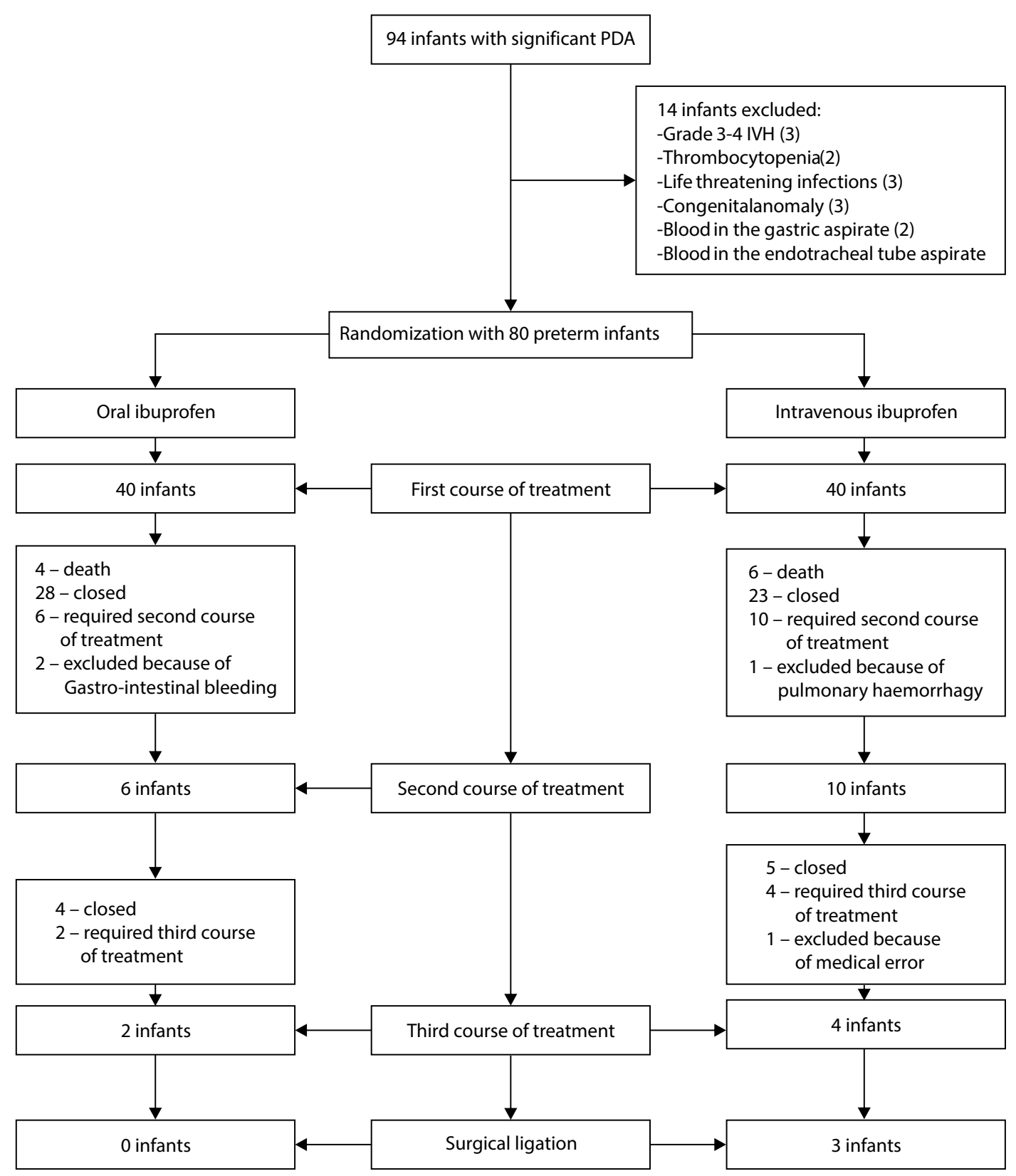

Fig. 1 Flow chart of the two randomized group (oral and intravenous group).

with $10(25 \%)$ in the intravenous ibuprofen group $(p=0.4)$. Two in the oral ibuprofen group $(5 \%)$ required a third course of drug therapy, compared with $4(10 \%)$ in the intravenous ibuprofen group.
There was no reopening of the ductus after closure was achieved. The cumulative closure rates were higher in both groups. Only three patients underwent surgical ligation $(7.5 \%)$ in the intravenous ibuprofen versus 0 in the oral ibuprofen group $(\mathrm{p}=0.23)$. 


\begin{tabular}{|c|c|c|}
\hline \multirow{2}{*}{ Characteristics } & Oral ibuprofen $(n=40)$ & Intravenous ibuprofen $(n=40)$ \\
\hline & $\mathrm{n}(\%)$ & n $(\%)$ \\
\hline \multicolumn{3}{|l|}{ Gestational age (week) } \\
\hline $28.1-30$ & $19(47.5)$ & $18(45)$ \\
\hline $30.1-32$ & $21(52.5)$ & $22(55)$ \\
\hline \multicolumn{3}{|l|}{ Birthweight（g) } \\
\hline$\leq 1000$ & $9(22.5)$ & $6(15)$ \\
\hline $1001-1500$ & $15(37.5)$ & $19(47.5)$ \\
\hline $1501-2000$ & $16(40)$ & $15(37.5)$ \\
\hline Male & $22(55)$ & $17(42.5)$ \\
\hline Delivery by cesarian section & $20(50)$ & $14(35)$ \\
\hline Antenatal indometacine & - & - \\
\hline Antenatal glucocorticoids & $26(65)$ & $18(45)$ \\
\hline Pulmonary hemorrhage & - & $2(5)$ \\
\hline Gastro-intestinal bleeding & $1(2.5)$ & 0 \\
\hline Perinatal asphyxia & $11(27.5)$ & $9(22.5)$ \\
\hline Various reason (human error) & 0 & $1(2.5)$ \\
\hline
\end{tabular}

\section{Table 2 Evaluation of renal function tests after first course of treatment}

\begin{tabular}{lllllll}
\hline \multirow{2}{*}{ Measurement } & \multicolumn{5}{l}{ Oral ibuprofen $(\mathrm{n}=36)^{*}$} & \multicolumn{4}{l}{ Intravenous ibuprofen $(\mathrm{n}=34)^{*}$} \\
\cline { 2 - 7 } & Before & After & $\mathrm{p}$ & Before & After & $\mathrm{p}$ \\
\hline $\mathrm{sCr}(\mathrm{mg} / \mathrm{dl} ; \mathrm{M} \pm \mathrm{SD})$ & $1.10 \pm 0.25$ & $1.07 \pm 0.23$ & 0.608 & $1.08 \pm 0.22$ & $1.085 \pm 0.24$ & 0.929 \\
$\mathrm{BUN}(\mathrm{mg} / \mathrm{dl} ; \mathrm{M} \pm \mathrm{SD})$ & $31.6 \pm 10.5$ & $31.3 \pm 8.7$ & 0.897 & $30.8 \pm 7.7$ & $31.6 \pm 9.9$ & 0.682 \\
$\mathrm{UO}(\mathrm{mg} / \mathrm{dl} ; \mathrm{M} \pm \mathrm{SD})$ & $3.2 \pm 1.0$ & $2.8 \pm 0.8$ & 0.071 & $3.08 \pm 0.85$ & $3.3 \pm 0.5$ & 0.192 \\
\hline
\end{tabular}

$s \mathrm{Cr}=$ serum creatinine concentration; $\mathrm{BUN}=$ blood urea nitrogen; $\mathrm{UO}=$ urine output, $\mathrm{M} \pm \mathrm{SD}=\mathrm{Mean} \pm$ Standard Deviation ${ }^{*} \mathrm{After} 1^{\mathrm{st}}$ course of treatment, 4 patients from the oral group and 6 from the intravenous group died, thus we evaluated renal function tests only for 36 patients in the oral group and 34 patients in the intravenous group.

\section{Table 3 Evaluation of renal function tests after second course of treatment}

\begin{tabular}{lllllll}
\hline \multirow{2}{*}{ Measurement } & \multicolumn{5}{l}{ Oral ibuprofen $(\mathrm{n}=6)$} & \multicolumn{4}{l}{ Intravenous ibuprofen $(\mathrm{n}=9)^{*}$} \\
\cline { 2 - 7 } & Before & After & $\mathrm{p}$ & Before & After & $\mathrm{p}$ \\
\hline $\mathrm{sCr}(\mathrm{mg} / \mathrm{dl} ; \mathrm{M} \pm \mathrm{SD})$ & $1.07 \pm 0.24$ & $1.09 \pm 0.24$ & 0.877 & $1.20 \pm 0.95$ & $0.97 \pm 0.45$ & 0.598 \\
$\mathrm{BUN}(\mathrm{mg} / \mathrm{dl} ; \mathrm{M} \pm \mathrm{SD})$ & $30.7 \pm 14.8$ & $30.4 \pm 13.7$ & 0.969 & $30.3 \pm 14.2$ & $30.6 \pm 14.0$ & 0.898 \\
$\mathrm{UO}(\mathrm{mg} / \mathrm{dl} ; \mathrm{M} \pm \mathrm{SD})$ & $2.7 \pm 0.6$ & $3.0 \pm 0.71$ & 0.167 & $3.2 \pm 0.65$ & $3.93 \pm 0.5$ & 0.045 \\
\hline
\end{tabular}

$s \mathrm{Cr}=$ serum creatinine concentration; $\mathrm{BUN}=$ blood urea nitrogen; $\mathrm{UO}=$ urine output, $\mathrm{M} \pm \mathrm{SD}=\mathrm{Mean} \pm \mathrm{Standard}$ Deviation. ${ }^{*} \mathrm{The}$ second course of treatment was undertaken for 6 patients in the oral group and 10 patients in the intravenous group, but given a medical error, one patient from the intravenous group was excluded from the evaluation of renal function tests after the second course of treatment.

In the evaluation of renal tolerance, none of the patients had oliguria. The $\mathrm{s} C \mathrm{r}$ levels and blood urea nitrogen before and after the treatment did not differ significantly for either the oral ibuprofen group or intravenous ibuprofen group (Table 2).
Renal function test results before and after the second course of treatment did not differ significantly for each group treatment (Table 3). In patients who underwent a second course of intravenous therapy, the urinary output was significantly decreased. 
The mortality rate was different between treatment groups, 4 patients (10\%) died in the oral ibuprofen group and 6 patients $(15 \%)$ died in the intravenous group $(\mathrm{OR}=0.63$, 95\% CI: 0.16-2.43; $\mathrm{p}=0.502)$.

\section{Discussion}

If oral ibuprofen is as efficient as intravenous ibuprofen, with no greater adverse effects, its simple administration and lower cost would be important advantages. Our results showed oral ibuprofen to be effective and safe in PDA closure, with 28 of our 40 (70\%) study infants achieving a successful outcome. Patients treated with Ibuprofen by intravenous route probably have much higher risk of a second course of therapy according to our study where $15 \%$ versus $25 \%$ underwent a second course of therapy, $(\mathrm{p}=0.4)$.

The rate of closure in the group assigned to intravenous ibuprofen after the complete treatment $(92.5 \%)$ was similar to rates previously reported by Van Overmeire and Lago $(5,12)$. Some trials on the use of oral ibuprofen for closure of PDA have been published recently $(17,18,19)$. All studies had small sample sizes. Aly et al. (20), in a randomized pilot study, reported that PDA was closed in 7 of 9 premature infants ( $\leq 35$ weeks) given oral ibuprofen and in 10 of 12 premature infants given intravenous indomethacin. Fakhraee et al. (21) in a randomized study, reported that PDA was closed in all 18 premature infants ( $\leq 34$ weeks) given oral ibuprofen and in 15 of 18 premature infants given oral indomethacin. The efficacy of oral ibuprofen compared with intravenous indomethacin was reported by Supapannachart et al. (22) and Chotigeat et al. (23) as well. In nonrandomized open trials, Heyman et al. (24) and Cherif et al. (25) reported ductal closure with oral ibuprofen respectively in $21(95.4 \%)$ of 22 patients and $38(95 \%)$ of 40 patients. The authors concluded that oral ibuprofen might constitute a feasible alternative in the treatment of PDA. Van Overmeire studied the efficacy of indomethacin and ibuprofen given to larger premature infants ( $\leq 32$ weeks) at the age of $2-4$ days. They reported that the closure rate was similar (66\% and 70\%, respectively) after the first course and that there was no significant difference in side effects, although ibuprofen was associated with significantly less impairment of renal function (26).

The previous study comparing oral and intravenous ibuprofen enrolled 64 preterm infants. That trial demonstrated that the rate of ductal closure tended to be higher in the oral group ( $84 \%$ versus $62 \%$ ). This study was not powered to detect differences in complications (25). The two studies increase the number of infants randomized and expand the information about the safety and efficacy of oral ibuprofen in more mature VLBW infants $(27,28)$.

In our study, patients treated with ibuprofen by intravenous route probably have a much greater risk of undergoing surgery $(7.5 \%$ versus $0, p=0.23)$. The same result was found by Cherif et al., (17) with the rate of closure of PDA marginally favorable in the oral ibuprofen group $(84.3 \%$ vs $62.5 \%, \mathrm{p}=0.04 ; 95 \%$ confidence interval: 0.99-1.84). Surgical ligation of the PDA was performed in $1(3.1 \%)$ patient in the oral ibuprofen group $\mathrm{O}$ and in $4(12.5 \%)$ patients in the intravenous group $(\mathrm{p}=0.25)$ (17).

Other recent studies support the notion that ibuprofen therapy is not devoid of renal effects in neonates $(29,30,31)$. Renal function test results before and after the second course of treatment did not differ significantly for each group treatment in our study, but patients who underwent a second course of intravenous therapy, urinary output was significantly decreased.

Gournay noted an increase in creatinine in the prophylactic ibuprofen group and in those who received a second course of ibu- 
profen, which resolved in the second week of life (31). They also noted a decrease in urine output, with ibuprofen as compared with a placebo, that returned to baseline after the first course. Ticker and Yildirim (29) described temporary oliguria and/or renal dysfunction after treatment with one course of ibuprofen that is similar to that seen with indomethacin. Vieux found a significant decrease in glomerular filtration and tubular function impairment in the ibuprofen group that was not seen in the patients who did not receive ibuprofen (30). Richards reported that the effectiveness of ibuprofen in closing a PDA decreased with a second course, and that creatinine was significantly higher in neonates receiving a second course as compared to controls (32).

In fact, ibuprofen seems less potent over COX-1, which is primarily involved in basal physiologic renal processes $(10,33)$. Renal adverse effects of ibuprofen seem to become disclosed when it is used with a prophylactic purpose. Such trials are characterized by an early administration, during the very first hours of life, as well as with a low gestational age of the enrolled patients (26). As previously stated by Hammerman and Kaplan (34), the potential benefit achieved by prophylactic closing of a PDA does not justify exposing all infants to a drug that is not needed by as many as twothirds of them, and which has potentially more serious side effects than the condition at which the preventive efforts are aimed. But, as in our study, renal failure has not been reported in any study using oral ibuprofen.

However, renal alterations may still occur during ibuprofen treatment, although they may be transient, and consist of a reversible decrease in UI or increase in $\mathrm{s} C \mathrm{r}$ concentration $(16,33)$. Since the renal tolerability of ibuprofen for renal function in the neonate is a major argument in favour of its use in the treatment of PDA $(27,28)$, our study expands our information about the safety and efficacy of oral ibuprofen in more mature VLBW infants. sCr levels and uremia in our patients were within the normal range at all times, so there was no contraindication for a second or third dose of ibuprofen when it was needed. This might be an explanation for the higher rate of pharmacologic ductal closure observed in our study.

The mortality rate in our study was higher in the intravenous group, $15 \%$ versus $10 \%$, $(p=0.5)$, this result is different from the results of Cherif et al., where the mortality rate was higher in the oral ibuprofen group: $28.1 \%$ in the oral group versus $25 \%$ in the intravenous group (17).

\section{Limitations of study}

There are several limitations to our study. This was an open-label, one-blind study. The physicians and nurses were aware of the nature of the study, although the cardiologist who supervised the echocardiographic studies was blind to the status of the infants and whether they were treated with oral ibuprofen or intravenous ibuprofen. This was the first experience that we have with ibuprofen (oral or intravenous) for treatment of PDA in preterm infants.

\section{Conclusion}

No statistically significant difference in efficacy and safety between the two treatments could be confirmed. Patients treated with ibuprofen by intravenous group have probably a much greater risk of undergoing surgery.

Authors' contributions: Conception and design: EP, $\mathrm{AH}$; Acquisition, analysis and interpretation of data: AH, IB, SB; Drafting the article: EP, AH; Revising it critically for important intellectual content: EP, IB.

Conflict of interest: The authors declare that they have no conflict of interest. 


\section{References}

1. Evans N, Kluckow M. Early ductal shunting and intraventricular haemorrhage in ventilated preterm infants. Arch Dis Child Fetal Neonatal Ed. 1996;75(3):F183-F186.

2. Martin CG, Snider AR, Katz SM, Peabody JL, Brady JP. Abnormal cerebral blood flow patterns in preterm infants with a large patent ductus arteriosus. J Pediatr. 1982;101(4):587-93.

3. Wong SN, Lo RN, Hui PW. Abnormal renal and splanchnic arterial Doppler pattern in premature babies with symptomatic patent ductus arteriosus. J Ultrasound Med. 1990;9(3):125-30.

4. Cotton RB, Stahlman MT, Kovar I, Catterton WZ. Medical management of small preterm infants with symptomatic patent ductus arteriosus. J Pediatr. 1978;92(3):467-73.

5. Van Overmeire B, Smets K, Lecoutere D, Van de Broek H, Weyler J, Degroote K. A comparison of ibuprofen and indomethacin for closure of patent ductus arteriosus. N Engl J Med. 2000;343(10):674-81.

6. Friedman WF, Hirschklau MJ, Printz MP, Pitlick PT, Kirkpatrick SE. Pharmacologic closure of patent ductus arteriosus in the premature infant. $\mathrm{N}$ Engl J Med. 1976;295(10):526-9.

7. Heymann MA, Rudolph AM, Silverman NH. Closure of the ductus arteriosus in premature infants by inhibition of prostaglandin synthesis. N Engl J Med. 1976;295(10):530-3.

8. Betkerur MV, Yeh TF, Miller K, Glasser RJ, Pildes RS. Indomethacin and its effect on renal function and urinary kallikrein excretion in premature infants with patent ductus arteriosus. Pediatrics. 1981;68(1):99-102.

9. van Bel F, Guit GL, Schipper J, van de Bor M, Baan J. Indomethacin-induced changes in renal blood flow velocity waveform in premature infants investigated with color Doppler imaging. J Pediatr. 1991;118(4 Pt 1):621-6.

10. Edwards AD, Wyatt JS, Richardson C, Potter A, Cope M, Delpy DT. Effects of indomethacin on cerebral haemodynamics in very preterm infants. Lancet. 1990;335(8704):1491-5.

11. Varvarigou A, Bardin CL, Beharry K, Chemtob S, Papageorgiou A, Aranda JV. Early ibuprofen administration to prevent patent ductus arteriosus in premature newborn infants. JAMA. 1996;275(7):539-44.
12. Lago P, Bettiol T, Salvadori S, Pitassi I, Vianello A, Chiandetti L. Safety and efficacy of ibuprofen versus indomethacin in preterm infants treated for patent ductus arteriosus: a randomised controlled trial. Eur J Pediatr. 2002;161(4):202-7.

13. Guignard JP. The adverse renal effects of prostaglandin synthesis inhibitors in the newborn rabbit. Semin Perinatol. 2002;26:398-405.

14. Allegaert K, Vanhole C, de Hoon J, Guignard JP, Tibboel D, Van Overmeire B. Nonselective cyclo-oxygenase inhibitors and glomerular filtration rate in preterm neonates. Pediatr Nephrol. 2005;20:1557-61.

15. Papile LS, Burstein J, Burstein R, Keffler H. Incidence and evolution of the subependymal intraventricular hemorrhage: a study of infants weighing less than 1500 grams. J Pediatr. 1978;92:529-34.

16. Kauffman RE, Nelson MV. Effect of age on ibuprofen pharmacokinetics and antipyretic response. J Pediatr. 1992;121:969-73.

17. Cherif A, Jabnoun S, Khrouf N. Oral ibuprofen in early curative closure of patent ductus arteriosus in very premature infants. Am J Perinatol. 2007;24(6):339-45.

18. Hariprasad P, Sundarrajan V, Srimathy G, Suthager B, Ramadevi BS. Oral ibuprofen for closure of hemodynamically significant PDA in premature neonates. Indian Pediatr. 2002;39(1):99-100.

19. Sangtawesin V, Sangtawesin C, Raksasinborisut C, et al. Oral ibuprofen prophylaxis for symptomatic patent ductus arteriosus of prematurity. J Med Assoc Thai. 2006;89 (3):314-21.

20. Aly H, Lotfy W, Badrawi N, Ghawas M, AbdelMeguid IE, Hammad TA. Oral ibuprofen and ductus arteriosus in premature infants: a randomized pilot study. Am J Perinatol. 2007;24(5):267-70.

21. Fakhraee SH, Badiee Z, Mojtahedzadeh S, Kazemian M, Kelishad R. Comparison of oral ibuprofen and indomethacin therapy for patent ductus arteriosus in preterm infants. Zhongguo Dang Dai Er Ke Za Zhi. 2007;9(5):399-403.

22. Supapannachart S, Limrungsikul A, Khowsathit P. Oral ibuprofen and indomethacin for treatment of patent ductus arteriosus in premature infants: a randomized trial at Ramathibodi Hospital. J Med Assoc Thai. 2002;85 (Suppl 4):S1252-S1258.

23. Chotigeat U, Jirapapa K, Layangkool T. A comparison of oral ibuprofen and intravenous indomethacin for closure of patent ductus arteriosus in 
preterm infants. J Med Assoc Thai. 2003;86 (suppl 3):S563-S569.

24. Heyman E, Morag I, Batash D, Keidar R, Baram S, Berkovitch M. Closure of patent ductus arteriosus with oral ibuprofen suspension in premature newborns: a pilot study. Pediatrics. 2003;112(5):e354.

25. Cherif A, Khrouf N, Jabnoun S, Mokrani C, Amara MB, Guellouze N, et al. Randomized pilot study comparing oral ibuprofen with intravenous ibuprofen in very low birth weight infants with patent ductus arteriosus. Pediatrics. 2008;122:1256-61.

26. Van Overmeire B, Allegaert K, Casaer A, Debauche C, Decaluwe' W, Jespers A, et al. Prophylactic ibuprofen in premature infants: A multicentre, randomised, double-blind, placebo-controlled trial. Lancet. 2004;364:19459.

27. Gokmen T, Erdeve O, Altug N, Oguz SS, Uras N, Dilmen U. Efficacy and safety of oral versus intravenous ibuprofen in very low birth weight preterm infants with patent ductus arteriosus. J Pediatr. 2011;158(4):549-554.e1.

28. Erdeve O, Gokmen T, Altug N, Dilmen U. Oral versus intravenous ibuprofen: which is better in closure of patent ductus arteriosus? Pediatrics. 2009; 123:e763.
29. Tiker F, Yildirim SV. Acute renal impairment after oral ibuprofen for medical closure of patent ductus arteriosus. Indian Pediatr. 2007;44(1):54-5.

30. Vieux R, Desandes R, Boubred F, Semama D, Guillemin F, Buchweiller MC. Ibuprofen in very preterm infants impairs renal function for the first month of life. Pediatr Nephrol. 2010;25(2):267-74.

31. Gournay V, Roze JC, Kuster A, Daoud P, Cambonie G, Hascoet JM. Prophylactic ibuprofen versus placebo in very premature infants: a randomised, double-blind, placebo-controlled trial. Lancet. 2004;364(9449):1939-44.

32. Richards J, Johnson A, Fox G, Campbell M. A second course of ibuprofen is effective in the closure of a clinically significant PDA in ELBW infants. Pediatrics. 2009;124(2):e287-e293.

33. Kelley MT, Walson PD, Edge JH, Cox S, Mortensen ME. Pharmacokinetics and pharmacodynamics of ibuprofen isomers and acetaminophen in febrile children. Clin Pharmacol Ther. 1992;52:181-9.

34. Hammerman C, Kaplan M. Primum non nocere: Prophylactic versus curative ibuprofen. Lancet. 2004;36:1920-2. 